\section{P-165 NATIONAL EPIDEMIOLOGIC PROFILE OF UPPER LIMB MUSCULOSKELETAL DISORDERS IN THE TUNISIAN WORKFORCE AND PREDICTIONS FOR 2026.}

1Ons Grissa, Mohamed Manita, Marouane Hayouni, Ines Rassas, Charfeddine Amri, Neila Chaari, Adnene Henchi, Mohamed Akrout, Ilhem Boussarssar, Irtyah Merchaoui. ${ }^{1}$ Faculty of Medicine of Monastir, University of Monastir, Tunisia

\subsection{6/OEM-2021-EPI.215}

Introduction Upper limb Musculoskeletal disorders (UL-MSDs) in occupationally active populations represent an important health issue that affect millions of people worldwide. They lead to high healthcare costs and represent a significant burden to the national economy.

Objectives To assess the incidence of UL- MSDs in the industrial private sector since 2000 and to determine projection for 2026.

Methods Using a national retrospective study that concerned all the Occupational MSDs reported to the Tunisian National Health Insurance Fund, in all industrial private sectors from January 2000 to May 2018, we gathered all the medical and administrative data available.

Results Six thousand and forty-two cases of UL-MSDs were totaled. Most of the declared occupational UL-MSDs were those of female workers (sex ratio=0.15). Moreover, the present study showed a young age of declaration of MSDs (44 \pm 7.5 years). The most common industrial sector affected was in textile manufacturing (63.9\%). Mono-site MSDs were significantly more prevalent in almost all the industrial sectors. Central district had a significantly higher yearly number of cases than the two others $(p<10-3)$. The study showed that approximately $71 \%$ of all initial medical certificates were reported by occupational health physicians graduated in Occupational Medicine. Seventy-two percent of these declarations were accepted by the recognition committee $(p=0.007)$. In 2026 , it is expected to count 2,626 new occupational declared UL-MSDs, with a crude prevalence in female workers 27 times as high as in male workers. The textile and clothing manufacture will remain the main affected sector by the ULMSDs till 2026.

Conclusion The risk of UL-MSDs in the Tunisian private sector workforce is considerable; it requires the implementation of rapid ergonomic preventive measures in the next decade. Further biomechanical and psycho-organizational studies of the most at-risk workstations in the Tunisian clothing industry are key to preventing these occupational disorders.

\section{P-166 WORKPLACE STUDY OF A LOADING AND UNLOADING AUTOCLAVE WORKSTATION IN THE STERILIZATION UNIT OF THE UNIVERSITY HOSPITAL OF MONASTIR- TUNISIA.}

${ }^{1}$ Irtyah Merchaoui, Marouen Hayouni, Hibat Allah Mosbah, Nesrine Mars, Ines Rassas, Charfeddine Amri, Neila Chaari, Adnene Hanchi, Mohamed Akrout. 'University of Monastir, Tunisia

\subsection{6/OEM-2021-EPI.216}

Introduction In sterilization units, autoclaves are commonly used to guarantee equipment asepsis in sensitive environment. They should be loaded many times a day to guarantee the continuity of medical activity.

Objectives At the behest of the hygiene department boss, following autoclave health workers complaints about low back and upper limb pain, we carried out an analysis of the activity in order to identify the main occupational risk factors and propose consequent ergonomic recommendations.

Methods We proceeded to activity analysis based on observation method and operators' interviews. We finally assessed the autoclave loading and unloading lumbar and musculoskeletal disorders (MSD) risks respectively through NIOSH and Ergorom analyses.

Results For the autoclave loading station, carrying of weight loads ranged from 5 to $40 \mathrm{~kg}$. The NIOSH recommended load limit ranged from 2.0 to $11.8 \mathrm{~kg}$ in the autoclave loading station, and from 1.4 to $11.4 \mathrm{~kg}$ in the unloading station with a risk of low back pain of $4 \%$ for men and 15\% for women. As for upper limb MSD, Ergorom analyses proved a high risk of tendonitis of the rotator cuff (dominant shoulder in flexion or abduction $>60^{\circ}$ in isometry or with heavy load bearing) and of elbow due to a 60 to $100^{\circ}$ flexion/contraction over $73 \%$ of the working time. For the unloading station, there was an overall risk related to the hand grip. The risk of tendonitis of both elbows was related to a 60 to $100^{\circ}$ prolonged flexion over $85 \%$ of the working time.

Conclusion In the light of the obtained results, in order to avoid MSDs and low back pain in healthcare technicians of the autoclave in the sterilization unit, we recommended the handling load of material to sterilize should be limited to 11 $\mathrm{kg}$ and the use of the trolleys preferably with adjustable height and with dynamic racks.

\section{P-169 INFLUENCE OF ORGANIZATIONAL JOB CHARACTERISTICS ON NURSES' OCCUPATIONAL WELLBEING.}

${ }^{1}$ Irtyah Merchaoui, Marouen Hayouni, Salma Kammoun, Ines Rassas, Mohamed Akrout, Jaques Malchaire, Neila Chaari. ' University of Monastir, Tunisia

\subsection{6/OEM-2021-EPI.217}

Introduction Nurses' well-being has become a point of interest due to their stressful environment and consequent possible burnout.

Objectives to assess the influence of Tunisian nurses' job perception on their occupational well-being and to identify its main determinants.

Methods Our exploratory survey of job perception included an ergonomic chronological observation of 55 workstations in Monastir and Mahdia university hospitals in order to evaluate workload factors. The choice of the observed positions was based on the type of care department, nurse age and gender. Nurses' occupational well-being determinants were identified through a questionnaire driven by the Karasek and satisfaction scales.

Results The analysis of nurse job strain has shown that direct care requiring higher cognitive demands represents $27.26 \%$ of the total working time while administrative activities represent a higher proportion of nursing work. Furthermore, painful postures and movements were observed during about 20\% of working time. Standing posture was adopted during 58.22\% of the total working time, while sitting position was adopted only for a quarter $(26.6 \%)$ of it.

Subjective perceived workload of occupational well-being was found to be higherthan on the day of activity observation. However, $69.1 \%$ of nurses felt stressed at work with a lack of autonomy and a lot of routine. They also reported to 
be under estimated by their supervisor while they are supported by their colleagues. In addition, most of them felt unsatisfied with their salary and were not confident in their career evolution.

Conclusion The discrepancy raised by our study between the real workload and the perceived well-being seems to be conditioned by organizational dysfunction and dissatisfaction with conditions of work performance. New organizational possibilities with brainstorming approaches of the nurses' work environment are recommended and are being built through interdisciplinary research-action studies.

\section{P-171 AIR RECIRCULATION IN VENTILATION SYSTEM AND ITS IMPACT ON TRICHLORAMINE EXPOSURES IN A SWIMMING POOL HALL: A NUMERICAL INVESTIGATION}

${ }^{1}$ Hélène Proulx, Maximilien Debia, Stéphane Hallé. 'École de technologie supérieure, Canada

\subsection{6/OEM-2021-EPI.218}

Introduction Trichloramine $(\mathrm{NCl} 3)$ is an irritant gas commonly found in the air of indoor swimming pool, causing health problems to swimmers and workers who are often exposed to this contaminant. ASHRAE recommends a supply air delivery rate of 4 to 8 air changes per hour to remove trichloramine in aquatic centers. However, the fraction of recirculated air can have a significant impact on the exposure level.

Objective The main objective of this study is to investigate the impact of air recirculation by mechanical ventilation systems on $\mathrm{NCl} 3$ exposures for five user groups: i) swimmers in the basin, ii) people sitting or iii) standing on the deck, iv) lifeguards in surveillance chairs and v) spectators in mezzanine area.

Methods Exposure to $\mathrm{NCl} 3$ levels in a $9300 \mathrm{~m} 3$ swimming pool hall located in Montreal (Canada) is evaluated with a computational fluid dynamic software (Fire Dynamic Simulator). Simulations are performed for five recirculation ratios starting from the reference case at $77 \%$ down to $0 \%(100 \%$ fresh air). Emission rate of $\mathrm{NCl} 3$ is based on equations found in literature for a fully occupied pool. The numerical model was experimentally validated with tracer gas injection in situ.

Results The tracer gas simulation results show good agreement with the experimental results. Compared to the reference case (77\% recirculation condition), a 100\% fresh air ventilation strategy decreases the $\mathrm{NCl} 3$ levels of the five groups from: i) $19 \%$, ii) $31 \%$, iii) $62 \%$, iv) $61 \%$ and v) $77 \%$, respectively.

Conclusion Reducing the recirculation rate reduces the $\mathrm{NCl} 3$ concentrations. However, recirculation of air has less impact on the concentrations in the breathing zones located near the water surface compared to the other zones. The best air quality improvement with the $100 \%$ fresh air strategy is for spectators. Other ventilation strategies have to be investigated to improve air quality in the lower breathing zones as well.

\section{P-175 UNDERSTANDING THE ASSOCIATION BETWEEN TREATMENT MODALITY VERSUS EMPLOYMENT STATUS AMONG PATIENTS WITH ORGAN FAILURE}

${ }^{1}$ Anil Adisesh, Vijay Kumar Chattu, Sumaya Dano, Istvan Musci, Nathaniel Edwards. ${ }^{1}$ University of Toronto, Canada

10.1136/OEM-2021-EPI.219
Objectives In advanced organ failure patients: (1) To study the association between treatment modality versus employment status, (2) To analyze socio-demographic profiles and deprivation status, and (3) To explore Return to Work (RTW) by analysis of self-reported employment status.

Methods This ongoing hospital based cross-sectional study used a convenience sample: 1070 patients with advanced organ failure requiring solid organ transplant (SOT) or dialysis pooled from the Comprehensive Psychosocial Research Data System at UHN, Toronto. Patient reported outcome measures, clinical and socio-demographic variables were collected from stable outpatients on iPads using electronic data capture (DAta Driven Outcomes System-DADOS, Techna Institute, UHN, Toronto). The Ontario Marginalization Index characterized material deprivation. Data was analyzed using STATA v16, logistic regression used multiple imputation by chained equations.

Results Of 1070 SOT recipients, 646 (60\%) were males with $424(40 \%)$ females. Almost half (49\%) were of White ethnicity, Black (23\%) followed by South Asians and East Asians. 63\% (646) had >12 years education, the kidneypancreas sub-group were highest $88 \%$ (30) then kidney, liver and dialysis with $65 \%, 62 \%$ and $59 \%$, respectively. $51 \%$ of dialysis patients had a yearly income of $\$ 70,000$. These results reflect the higher employment status of kidney (60\%), liver (55\%) and kidney-pancreas (51\%) transplants compared to dialysis patients (28\%). 59\% of dialysis patients had high deprivation. The association between treatment modality vs employment status and employment status vs deprivation remained statistically significant after adjusting for age, sex, ethnicity and comorbidities in logistic regression models.

Conclusion SOT was associated with significantly higher odds of employment and lower material deprivation. Dialysis, transplant and occupational health professionals should support SOT and dialysis patients overcoming barriers to maintain and RTW. RTW post-SOT is complex and likely associated with personal, professional, societal and medical factors.

\section{P-177 TEMPORARY AND PERMANENT AUDITORY EFFECTS ASSOCIATED WITH OCCUPATIONAL CO-EXPOSURE TO LOW LEVELS OF SOLVENTS AND NOISE}

${ }^{1}$ Adriana Lacerda, Vanessa Bohn, Maria Renata José, Simone Mariotti Roggia, Fernanda Zuck, Benoît Pouyatos, Thomas Venet, Edward Krieg, Thais C Morata. ${ }^{1}$ Universidade Tuiuti do Parana, Brazil

\subsection{6/OEM-2021-EPI.220}

Introduction The effect of combined exposures to noise and solvents on hearing has been studied for decades, but the characterization of the risk is incomplete.

Objective To assess the temporary and permanent auditory effects associated with occupational co-exposures to low levels of solvents and noise.

Method Cross-sectional study with 25 printing industry workers (mean age 36.2 years) simultaneously exposed to low levels of solvents and noise $(<8 \quad 0$ dBA TWA). The control group composed of 29 industry workers (mean age 36.7 years) without exposure to noise and/or solvents. Participants answered a questionnaire and underwent pure-tone audiometry (PTA), acoustic immittance tests, auditory brainstem response 